\title{
SELECTION OF SUITABLE URBAN TOLLING SYSTEM TECHNOLOGY
}

Article deals with the selection of suitableselection urban tolling system technology. In the paper, a lot of aspects, which have an influence on selection of particular technology in city conditions, were considered. For example: charging policy, user aspects, technical aspects and economic aspects. Although the analysis was not performed within specific conditions of a particular city, it was found out that in spite of general analysis, it is possible to form relevant and rather clear conclusions.

Keywords: Urban tolling system, tolling technology, on-board unit.

\section{Introduction}

Selection of technological solution is an important phase when deploying urban tolling system[1 - 4]. It is important to realise that selection of technology is not the first step of system deployment. In principle it applies that technology should not determine other aspects of objective system [5 - 7]. The reverse should be true. It means that technological solution should be a result of complex evaluation of many technical and non-technical requirements, objective and subjective requirements, aspects, parameters and criteria (often political ones, even at municipal level) [8 - 10].

Selection of technology itself should be preceded by the following phases (Table 1):

- identification of transport problems within city and its neighbourhood,

- selection of measures for solution of transport problems not only in context of city itself but within the whole agglomeration; one of these measures may be transport charging (maybe together with restriction) and then targets of charging (deployment of toll) have to be defined - the most frequent ones like traffic and environmental, or economic targets,

- defining pricing policy - especially setting the kind and form of charging, period of validity and so on,

- selection of organisational structure - mainly relates to selection of operation of urban tolling system (for example city itself, city organisation, commercial subject, PPP) and therefore indirectly with financial assurance of the project.

The selection of technological solution (in connection with the previous phases) is closely related to practical operation of system - with procedures and processes on the level of front office and back office levels as well.

Phases of tolling system deployment Table 1

\begin{tabular}{|c|l|}
\hline Order & Phase \\
\hline 1 & Identification of transport problems \\
\hline 2 & $\begin{array}{l}\text { Selection of measures for solution of transport problems } \\
\text { Defining the objectives of charging }\end{array}$ \\
\hline 3 & Defining the pricing policy \\
\hline 4 & Selection of organisational structure \\
\hline 5 & $\begin{array}{l}\text { Selection of technology } \\
\text { Elaboration of processes }\end{array}$ \\
\hline 6 & $\begin{array}{l}\text { System deployment } \\
\text { Pilot (testing) operation } \\
\text { Personnel training } \\
\text { Marketing - info campaign }\end{array}$ \\
\hline 7 & Regular system operation \\
\hline
\end{tabular}

From the above-mentioned steps, it is clear that several mentioned phases are interconnected.

\section{Aspects affecting technology selection}

Generally possible technological solutions for urban tolling system can be identified as follows [11]:

- non-technical solution (kiosks and terminals similar to ones for payment of parking fee),

system with barriers,

\footnotetext{
* Karol Hrudkay

University Science Park, University of Zilina, Slovakia

E-mail: hrudkay@uniza.sk
} 
- DRSC (Dedicated Short-Range Communications) - in principle here may be included solutions based on RFID (Radio Frequency Identification) as it is similar technology,

- GNSS/CN (Global Navigation Satellite System\&Cellular Network),

- ANPR (Automatic Number Plate Recognition),

- odometer.

Aspects affecting selection of technological

solution for urban tolling system

Table 2

\begin{tabular}{|l|l|}
\hline 1 & Object of charging \\
\hline 2 & Principle of charging \\
\hline 3 & Range of charging \\
\hline 4 & Charged unit \\
\hline 5 & Number of charged units per time unit \\
\hline 6 & User identification \\
\hline 7 & Toll payment means \\
\hline 8 & Mode of individual types of participants \\
\hline 9 & Number of individual types of participants \\
\hline 10 & Enforcement intensity \\
\hline 11 & Toll system deployment costs \\
\hline 12 & Toll system operational costs \\
\hline 13 & Effectiveness of toll collection \\
\hline 14 & Toll system deployment time \\
\hline 15 & Flexibility of tolling system \\
\hline 16 & Initial costs for participant \\
\hline 17 & Suitability/simplicity in term of participant \\
\hline 18 & Compatibility/interoperability \\
\hline 19 & $\begin{array}{l}\text { Practical aspect - technology maturity, experience with } \\
\text { deployment and operation }\end{array}$ \\
\hline 20 & Perspective \\
\hline 21 & Support of added value services \\
\hline 22 & Affecting of traffic flow \\
\hline & \\
\hline
\end{tabular}

The question is which solution is the most suitable for specific conditions of a particular city.

The aspects (Table 2) [11] which affect selection of technological solution for urban tolling system can be divided into following groups:

- aspects of charging policy,

- user aspects,

- technological aspects,

- economical aspects.

It is not possible to describe and evaluate individual aspects while details of intention for deployment of tolling system are not known (e.g. in Bratislava conditions). Although the following analysis is in principle general, it is possible to deduce such outputs which are relevant for small or middle-sized cities.

\subsection{Aspects of charging policy and user aspects}

Among aspects determining single framework of charging we can include:

- object of charging,

principle of charging,

- range of charging,

charged unit,

mode of individual types of participants,

while these aspects are hardly known and we can possibly presume that even in case of political decision (though at municipal level) on deployment of urban tolling system, these aspects will be an object of serious discussions and will probably underlie relatively frequent and considerable changes.

In terms of user, there are especially important aspects directly connected with one's duties and restrictions. From this point of view an essential aspect is:

- $\quad$ suitability/simplicity with respect to participant who primary evaluates requirements on the user from point of view of processes and their complexity and possible demands on operation of technical devices (OBU, user terminals, ...), while secondly this aspect includes even other aspects with relevant effect on participant.

From aspects of charging policy it is, for example:

mode of particular types of users,

or from technical aspects the important ones are:

- user identification (especially obligatory OBU),

payment means,

affecting of traffic flow (especially if it is non-free flow system).

In terms of above mentioned aspects, the following elements as the most crucial ones were identified:

- $O B U$, i.e. if system is (not) based on use of vehicle unit,

detection of zone boundaries because zone charging is typical for urban tolling systems,

detection of vehicle movement within the zone enables to charge even the vehicles which are staying and realising its performance within the zone (such as an alternative to a possible charging based on time spent within zone),

affecting of user driving (not affecting="free flow"/lower speed/ stopping/delaying)

The graph in Fig. 1 shows how individual solutions cope within four mentioned crucial elements.

From this graph, it is clear that ANPR is a suitable candidate for applied technology which meets the above mentioned elements (without OBU, detection of zone boundary and area, free flow). In case that solution based on OBU is acceptable, solutions based on DSRC or GNSS/CN are also suitable (GNSS/CN technology maturity has to be proven in the real urban environment).

Solution based on odometer is specific, it is not verified in conditions of the city - only Swiss national tolling system is based on odometer; in this case interconnection of OBU with vehicle is 


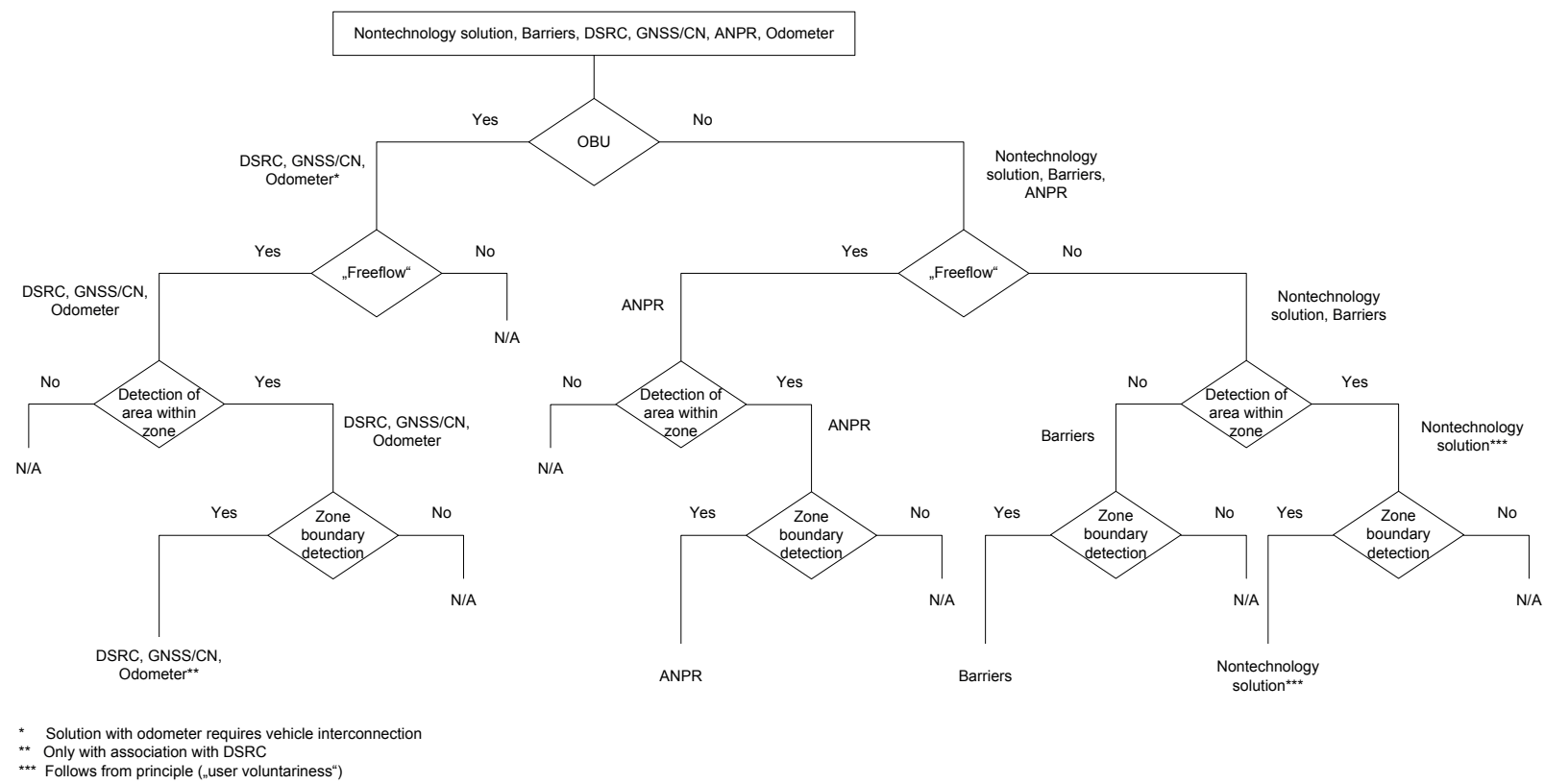

Fig. 1 Reviewing technological solutions in terms of essential aspects of charging policy and user aspects

necessary (except for connection to electricity supply) and such solution would be reasonable only in determination of tolling system according to performance of vehicle in the zone (distance travelled).

\subsection{Technological and economic aspects}

Technological and economic aspects affecting selection of technological solution are:

- identification of participant - defines the exactness of user identification, reliability of user determination or need to perform some additional steps on this determination,

- toll payment means - it is an aspect whether the solution enables/supports the broadest ways of toll payment including certain time freedom,

- intensity of enforcement - it is being evaluated if particular solution enables to reach required intensity of enforcement by adequate resources, or if some processes following from the basis of solution have essential effect on enforceability/ effectiveness of enforcement,

- costs on deployment of toll system reflect qualitative conception on investment demands,

- operational costs - it reflects qualitative conception on operational costs including expected future technology renewal,

- effectiveness of toll collection - typical standard for urban tolling systems is approximately within $90 \%-95 \%$ and in this case accessibility of this standard is evaluated or if implementation of a particular solution assumes processing aspects which can affect effectiveness of toll collection,

time for deployment of tolling system - largely reflects the need of toll infrastructure establishment (so called technological part) within urban environment and related time requirements (including related bureaucracy),

- flexibility of tolling system - it reflects ability of solution to adapt to variable conditions (mainly to aspects of charging policy) in adequate time and with adequate costs,

compatibility/interoperability - it reflects if solution with adequate costs is or may be compatible or interoperable with other tolling systems - in conditions of Slovakia only the national tolling system can be considered. However, in the future there may be also other urban tolling systems or city parking systems, even cross-border interoperability can be admitted, e.g. fictitiously Bratislava-Vienna (rem.: in terms of obligation to reach interoperability, Directive on interoperability 2004/52/EC [12] does not relate to systems which do not use OBU as well as urban systems where costs to achieve interoperability would be disproportionate to benefits), technology maturity, experience - it characterises experience with applied technology at least in the European context including estimation of possible future mid-term development, perspective - it evaluates technology in the framework of its expected deployment in defined time (in the framework of procurement procedure, such period is usually defined for 10-15 years) and its possible further use,

support of value added services - it reflects possibilities of technology to provide wide variety of value added services (using technical means or obtained data), 
Weight assigned to particular technical and economic aspects and their evaluation

Table 3

\begin{tabular}{|c|c|c|c|c|c|c|c|}
\hline Aspect & Weight [\%] & Non-technical & Barriers & ANPR & DRSC & GNSS/CN & Odometer \\
\hline User identification & 9 & -3 & 2 & 2 & 3 & 3 & 3 \\
\hline Toll payment means & 8 & -2 & 1 & 3 & 3 & 3 & 2 \\
\hline Enforcement intensity & 10 & -2 & 0 & 3 & 3 & 3 & 3 \\
\hline Costs on deployment of tolling system & 9 & 3 & 2 & 1 & -2 & -1 & -2 \\
\hline Tolling system operational costs & 11 & 3 & 2 & 0 & -1 & -2 & -1 \\
\hline Effectiveness of toll collecting & 10 & -3 & 2 & 1 & 2 & 2 & 2 \\
\hline $\begin{array}{l}\text { Time for deployment of tolling } \\
\text { system }\end{array}$ & 4 & 3 & 2 & 1 & -1 & 0 & -1 \\
\hline Flexibility of tolling system & 5 & -2 & 1 & 0 & -1 & 3 & -1 \\
\hline Compatibility/interoperability & 3 & -3 & -3 & 0 & 1 & 2 & -1 \\
\hline Technology maturity, experience & 7 & -2 & -1 & 3 & 2 & 0 & 0 \\
\hline Perspective & 5 & -3 & -3 & 2 & 1 & 2 & 0 \\
\hline Support of value added services & 4 & -2 & -2 & 1 & 0 & 3 & 0 \\
\hline $\begin{array}{l}\text { Number of users, number of } \\
\text { transactions per defined time period }\end{array}$ & 5 & 0 & -3 & 2 & 2 & 3 & 2 \\
\hline Affecting the traffic flow & 10 & -1 & -3 & 3 & 3 & 3 & 3 \\
\hline \multicolumn{2}{|l|}{ Weighted average } & -0.87 & 0.15 & 1.7 & 1.25 & 1.58 & 0.96 \\
\hline \multicolumn{2}{|l|}{ Overall ranking } & 6 & 5 & 1 & 3 & 2 & 4 \\
\hline
\end{tabular}

\begin{tabular}{|lccc|}
\hline Legend: & & & \\
\hline-3 & critical drawback & -3 & critical drawback \\
-2 & relevant drawback & -2 & relevant drawback \\
-1 & drawback & -1 & drawback \\
0 & neutral rating & & \\
\hline
\end{tabular}

- number of users, number of transactions per defined time period - it characterises system dimensioning, possibilities or restrictions of system to completely serve certain absolute number of participants or in defined time period (for example in traffic jam), including further extension,

- affecting the traffic flow - it reflects to what extent tolling system affects fluency of traffic flow (need to slow down vehicle, stop vehicle, need to use particular entrance/transit and so on); ideal solution does not affect traffic flow (so called free flow solution).

From the above mentioned, it is clear that if aspects of charging policy are not defined specifically, it is not possible to assess individual aspects for particular solutions either in qualitative or in quantitative way.

From this reason, the relatively complex technical aspects affecting the selection of technological solution of urban tolling system qualitatively are assessed by the following procedure [13]:

1. method of 'survey among experts' was used for qualitative assessment of individual aspects.

2. addressed experts assigned importance to individual aspects which characterises the seriousness of given aspect in complete interpretation.
3. the experts further evaluated individual aspects according to the fact whether a particular solution fulfils given criteria in a standard way, if it is for solution fundamental or relevant drawback or advantage.

Average weights and assessments of the individual aspects are shown in Table 3 (more accurate mentioned values are median ones).

With respect to meeting the requirements imposed by technical and economic aspects within the meaning of the following table, the most suitable solutions are offered by ANPR (as the only one without negative evaluation of any aspect) and GNSS/CN with similar evaluation. Following in the order is DSRC solution. As absolutely inappropriate solutions appear nontechnical solutions and solutions based on the barriers.

\section{Characteristics of technological solutions}

Moreover, each of the mentioned options of urban tolling system is characterised by essential properties which can play an important role when selecting technological solution. In a nutshell, these features for all six solutions are mentioned in Table 4. 
Essential typical features of technological solutions

Table 4

\begin{tabular}{|c|c|c|}
\hline Technological solution & Advantages & Disadvantages \\
\hline Non-technological solution & $\begin{array}{l}\text { Simplicity } \\
\text { Relatively cheap solution (deployment and operation ) } \\
\text { Solution without OBU }\end{array}$ & $\begin{array}{l}\text { Need to build network of terminals } \\
\text { Low effectiveness of toll collecting } \\
\text { "Non-free flow“ solution (because of payment) } \\
\text { Problematic enforcement }\end{array}$ \\
\hline Barriers & $\begin{array}{l}\text { Simplicity } \\
\text { Relatively cheap solution (deployment and operation ) } \\
\text { Solution without OBU }\end{array}$ & $\begin{array}{l}\text { "Non-free flow" solution } \\
\text { Low throughput } \\
\text { Necessary construction changes } \\
\text { Cash problem (if admitted) }\end{array}$ \\
\hline ANPR & $\begin{array}{l}\text { Solution without OBU } \\
\text { The same technology either } \\
\text { for charging or enforcement } \\
\text { Proven (the most applied) technology } \\
\text { "Free flow" solution }\end{array}$ & $\begin{array}{l}\text { Need for infrastructure deployment } \\
\text { (for charging and for enforcement as well) } \\
\text { Possible lower effectiveness of toll collection }\end{array}$ \\
\hline DRSC & $\begin{array}{l}\text { Proven solution } \\
\text { "Free flow" solution }\end{array}$ & $\begin{array}{l}\text { Need of OBU } \\
\text { Need for establishment of infrastructure } \\
\text { (for charging as well as for enforcement) }\end{array}$ \\
\hline GNSS/CN & $\begin{array}{l}\text { "Free flow" solution } \\
\text { Advanced solution } \\
\text { Multiplicative use (possibility to provide } \\
\text { services with added value) } \\
\text { The minimum infrastructure (only enforcement) } \\
\text { Support of several ways of payment } \\
\text { Flexibility }\end{array}$ & $\begin{array}{l}\text { Non-verified solution (only pilot projects) } \\
\text { Need of OBU } \\
\text { Expensive OBU }\end{array}$ \\
\hline Odometer & $\begin{array}{l}\text { "Free flow" solution } \\
\text { Practical relevance only at charging } \\
\text { according to distance travelled }\end{array}$ & $\begin{array}{l}\text { Need of OBU and its connection with vehicle } \\
\text { Solution without practical example } \\
\text { within urban environment }\end{array}$ \\
\hline
\end{tabular}

\section{Conclusions}

From the above mentioned analysis of partial conclusions and foreign experience it can be concluded that main candidates for technological solution of up-to-date urban tolling system are ANPR, DSRC, GNSS/CN.

From these potential solutions of urban tolling system, ANPR solution does not require $\mathrm{OBU}$ what is an essential advantage . At the same time, this solution is the most extended solution in Europe and in the world and meets all placed requirements at least within standard level.

However, the other two solutions are based on the use of vehicle OBU which in case of charging of cities and thus mostly of passenger cars can be perceived as an obstacle and has many procedural, logistic and financial consequences on the side of charging organisation, or operator of such system as well.

DSRC is a well proven technology, especially on the level of national tolling systems. In case of urban tolling systems, in the past there were even cases when DSRC technology was replaced by ANPR technology.
Last solution which is appropriate, is the satellite - based solution whose basic disadvantage is its practical non-verification (except for realised pilot projects). Such solution still remains challenge and it can be expected that in close future such systems will not arise. They will probably get chance in mediumterm horizon with EGNSS (Galileo) use and development of telematics within vehicles.

\section{Acknowledgements}

This paper is supported by the following project: University Science Park of the University of Zilina (ITMS: 26220220184) supported by the Research\&Development Operational Program funded by the European Regional Development Fund.

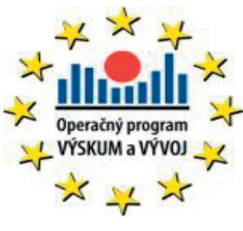




\section{References}

[1] PICKFORD, A. T. W., BLYTHE, P. T: Road User Charging and Electronic Toll Collection, Artech House, 2006.

[2] NUMRICH, J., RUJA, S., VOSS, S.: Global Navigation Satellite System Based Tolling: State-of-the-art, Netnomics, 13:93-123, 2012, Springer.

[3] SANTOS, G., NEWBERY, D.: Urban Congestion Charging: Theory, Practice and Environmental Consequences, CESifo Workshop on Environmental Economics and the Economics of Congestion, Venice, June 2001, ISSN 1617-9595, pp. 20.

[4] HYMAN, G., MAYHEW, L.: Optimizing the Benefits of Urban Road User Charging, Transport Policy, 9, 2002, pp. 189-207, Elsevier.

[5] HRUDKAY, K.: Technology and Interoperability of Electronic Toll Collection in Slovak Conditions (in Slovak), PhD thesis, Department of Telecommunications: Faculty of Electrical Engineering: University of Zilina, 2010, 108 p.

[6] HERICKO, M., HERICKO, M., ZIVKOVIC, A.: An Evaluation of Different Functional Solutions for Satellite-Based Tolling in Europe, Proc. of the $44^{\text {th }}$ Hawaii International Conference on System Sciences, 2011.

[7] HIURA, R., YAMAGUCHI, T., MABUCHI, Y., OKAZAKI, T., IEHARA, M., FUKASE, T.: System Evaluation Test of Global Navigation Satellite System-based Road Pricing System, Mitsubishi Heavy Industries Technical Review, vol. 50, No. 4, 2013.

[8] Transport Regulatory Uses of Telematics in Europe, vol. 2, Report prepared for Transport Certification Australia Limited, Rapp Trans Ltd, 2008.

[9] MADLENAK, R., MADLENAKOVA, L.: The Proposal of Digital Advertising System, TELECOM 2013 - Telecommunications in the context of globalization: $21^{\text {st }}$ national conference with foreign participation, October 2013, Sofia: Publishing group of the Union of Scientists in Bulgaria, CD-ROM, pp. 11-20, ISSN 1314-2690.

[10] MIKULA, J., HRUDKAY, K., DZIMKOVA, R.: Utilisation of Toll Data (in Slovak), Research Report, 1/2013, Transport Research Institute Zilina, Slovakia.

[11] HRUDKAY, K.: Aspects Affecting the Selection of Urban Tolling Technology - Part 1 (in Slovak), Svet dopravy [electronic source]: science - reviewed online journal, 21 May, 2015, online, ISSN 1338-9629.

[12] Directive 2004/52/EC of the European Parliament and of the Council of 29 April 2004 on the interoperability of electronic road toll systems in the Community.

[13] MIKULA, J., HRUDKAY, K., DZIMKOVA, R., BADO, J., HRONSKY, P., ZUZIAK, L., GENZOR, P.: Urban Tolling Systems (in Slovak), Research report, 1, 2013, Transport Research Institute Zilina, Slovakia. 